\title{
Nebivolol Attenuates Maladaptive Proximal Tubule Remodeling in Transgenic Rats
}

\author{
Melvin R. Hayden ${ }^{a, c}$ Javad Habibi ${ }^{a, c, d}$ Adam Whaley-Connell ${ }^{a, c, d}$ \\ Dilek Sowers $^{c}$ Megan Johnson ${ }^{a, c}$ Roger Tilmon ${ }^{c}$ Deepika Jain ${ }^{a, c}$ \\ Carlos Ferrario $^{\mathrm{e}}$ James R. Sowers ${ }^{\mathrm{a}-\mathrm{d}}$
}

Departments of a Internal Medicine and ${ }^{b}$ Physiology and Pharmacology, ${ }^{c}$ Diabetes Cardiovascular Center, University of Missouri-Columbia School of Medicine, ${ }^{\mathrm{d}}$ The Harry S. Truman VA Medical Center, and

eHypertension and Vascular Disease Center, Wake Forest University School of Medicine, Columbia, Mo., USA

\section{Key Words}

NADPH oxidase $\cdot$ Proximal tubule cell $\cdot$ Megalin

\begin{abstract}
Background/Aims: The impact of nebivolol therapy on the renal proximal tubular cell (PTC) structure and function was investigated in a transgenic (TG) rodent model of hypertension and the cardiometabolic syndrome. The TG Ren2 rat develops nephropathy with proteinuria, increased renal angiotensin II levels and oxidative stress, and PTC remodeling. Nebivolol, a $\beta_{1}$-antagonist, has recently been shown to reduce albuminuria, in part, through reductions in renal oxidative stress. Accordingly, we hypothesized that nebivolol therapy would attenuate PTC damage and tubulointerstitial fibrosis. Methods: Young Ren2 (R2-N) and SD (SD-N) rats were treated with nebivolol (10 mg/ $\mathrm{kg} /$ day) or vehicle (R2-C; SD-C) for 3 weeks. PTC structure and function were tested using transmission electron microscopy and functional measurements. Results: Nebivolol treatment decreased urinary $\mathrm{N}$-acetyl- $\beta$-D-glucosaminidase, tubulointerstitial ultrastructural remodeling and fibrosis, NADPH oxidase activity, 3-nitrotyrosine levels, and increased megalin and lysosomal-associated membrane protein-2 immunostaining in PTCs. UI-
\end{abstract}

trastructural abnormalities that were improved with therapy included altered canalicular structure, reduced endosomes/ lysosomes and PTC vacuoles, basement membrane thickening, and mitochondrial remodeling/fragmentation. Conclusion: These observations support the notion that nebivolol may improve PTC reabsorption of albumin and other glomerular filtered small molecular weight proteins in association with the attenuation of oxidative stress, tubulointerstitial injury and fibrosis in this rat model of metabolic kidney disease.

Copyright $\odot 2010$ S. Karger AG, Basel

\section{Introduction}

Increases in the prevalence of the metabolic syndrome and diabetes play an important role in the increasing incidence of chronic kidney disease [1-3]. The histopathological feature that is most strongly linked to progressive renal impairment is proximal tubule cell (PTC) injury and tubulointerstitial fibrosis [4-6]. Microalbuminuria is an important early clinical indicator of progressive kidney disease in association with the metabolic syndrome and diabetes [1-3]. PTCs normally reabsorb most of the

\section{KARGER}

(C) 2010 S. Karger AG, Basel

Fax +41613061234

E-Mail karger@karger.ch

www.karger.com
Accessible online at: www.karger.com/ajn
James R. Sowers, MD, University of Missouri-Columbia School of Medicine

Department of Internal Medicine

Division of Endocrinology, Diabetes and Metabolism

One Hospital Dr., Columbia, MO 65212 (USA)

Tel. +1 573884 0769, Fax +1 573884 5530, E-Mail sowersj@ health.missouri.edu 
glomerular-filtered protein, so only $30 \mathrm{mg}$ or less appears in the urine [7-14]. Further, there is increasing evidence that growth factors such as angiotensin II (Ang II), in conjunction with filtered proteins, can exert direct injury to the PTC resulting in tubulointerstitial fibrosis.

Albumin and other small molecular proteins filtered through the glomerulus are processed by PTC by at least two distinct pathways and most of the filtered albumin is returned to the peritubular blood by a retrieval pathway [11-15]. Compelling evidence for the importance of this retrieval pathway has been provided by two-photon microscopy [16]. These studies have demonstrated that large vesicles laden with intact albumin track through the PTC from the apical to the basolateral regions. This process is disrupted by elevated tissue levels of Ang II. Albumin retrieval can be restored through Ang II blockade [7, 9-20]. Smaller quantities of filtered proteins that are not retrieved undergo lysosomal degradation before urinary excretion as small peptide fragments [17, 21]. This degradation pathway is especially susceptible to metabolic and growth factors such as Ang II, responsible for maladaptive changes in the PTC and consequent tubulointerstitial fibrosis [10-20].

A continuous and extensive microvilli brush border covers the apical portion of the PTC providing the increased surface area responsible for receptor-mediated endocytosis of albumin and other small molecular weight proteins. The protein megalin is localized in the brush border microvilli in association with canalicular structures, clathrin-coated pits, endocytic vesicles and recycling endosomes, and facilitates this receptor-mediated protein endocytosis $[21,22]$. Albumin and other small molecular weight proteins are subsequently disassociated from these receptors, degraded into their constituent polypeptides and amino acids via the endosomal/lysosomal degradation pathway, and then transported across the basement membrane of the PTC and absorbed by adjacent interstitial capillaries [22, 23].

There is evidence that activation of the kidney reninangiotensin system (RAS) plays a crucial role in PTC maladaptive structural remodeling and functional abnormalities by increasing oxidative stress [24-29]. Increased intrarenal Ang II has been reported in transgenic Ren2 rats [23-26, 30], which also manifest activation of the sympathetic nervous system (SNS) as reflected by elevated levels of norepinephrine [31]. In this regard, $\beta$-adrenergic receptor blockers suppress the SNS tissue response and renal secretion of renin [32, 33]. These data facilitate the notion that $\beta$-blockers could reduce PTC injury and remodeling in scenarios involving both RAS and SNS activation such as exists in the transgenic Ren2 rat that manifests progressive albuminuria $[3,7,26]$.

Nebivolol is a $\beta_{1}$-antagonist blocker which is known to increase tissue nitric oxide (NO) bioavailability and reduce NADPH oxidase activity [34-38]. Currently, there are limited studies exploring the impact of nebivolol treatment on the kidney in animal models displaying tubulointerstitial injury [39-42]. Recently, we observed that nebivolol treatment in Ren2 rats reduced proteinuria, and increased the podocyte-specific markers podocin and desmin [34]. Interestingly, the glomerular protective effects of nebivolol were very modest compared with prior intervention studies utilizing RAS blockade [26, 28] and could not explain the substantive reductions in albuminuria that were observed [34]. To further explore its renal protective effects, we investigated the impact of nebivolol treatment on PTC and tubulointerstitial abnormalities in Ren2 rats.

\section{Material and Methods}

Animals and Treatments

Male Ren2 and age-matched SD rats (6-9 weeks) were randomly assigned to control (R2-C and SD-C) or nebivolol-treated groups $(\mathrm{R} 2-\mathrm{N}$ and $\mathrm{SD}-\mathrm{N})(\mathrm{n}=5)$. Nebivolol-treated rats received $10 \mathrm{mg} / \mathrm{kg} /$ day released via an implanted osmotic mini-pump for 21 days. All procedures were approved by the University of Missouri Animal Care Committees and housed in accordance with NIH guidelines. Blood pressure was measured in triplicate using the tail-cuff method prior to initiation of treatment and prior to sacrifice at 21 days [34]. Urine protein and $\beta-\mathrm{NAG}$ were determined using automated colorimetric assays $[9,34]$.

\section{Transmission Electron Microscopy (TEM)}

Renal cortical tissue was thinly sliced and placed immediately in primary TEM fixative stained with $5 \%$ uranyl acetate and triple-lead stain $[9,26]$. To maintain uniformity, only S-1 segments of the PTC with identifiable microvilli that were immediately adjacent to glomeruli were examined.

\section{Megalin- and Lysosomal-Associated Membrane Protein-2 \\ Immunohistochemistry}

Briefly, 4- $\mu \mathrm{m}$ sections were incubated with 1:50 goat antimegalin or megalin- and lysosomal-associated membrane protein-2 (LAMP2) antibody overnight and then incubated with 1:300 anti-goat Alexa flour 647 for $4 \mathrm{~h}$ and viewed with a confocal laser-scanning microscope. Images were captured by LSM imaging system and intensities quantified by MetaVue as average gray scale intensities.

\section{NADPH Oxidase and Subunits (Rac1 and p47phox) and \\ 3-Nitrotyrosine (3-NT) Content}

NADPH oxidase activity was determined in kidney cortical tissue by a spectrophotometric technique $[9,26]$. Racl and $\mathrm{p} 47^{\mathrm{phox}}$ sections were incubated with 1:200 Racl primary antibody or 
1:100 goat polyclonal $\mathrm{p} 47^{\text {phox }}$ in tenfold diluted blocking agent overnight. Sections were incubated with 1:300 anti-goat for p47phox and anti-mouse for Racl for $4 \mathrm{~h}$; signal intensities were then analyzed [26]. For 3-NT, sections were incubated with 1:200 primary rabbit polyclonal anti-nitrotyrosine antibody overnight, washed and incubated with secondary antibodies, biotinylated linked and strepavidin HRP for 30 min each. Diaminobenzidine was applied for $7 \mathrm{~min}$, sections rinsed again and stained with hematoxylin for $45 \mathrm{~s}$, rehydrated, and images captured and signal intensities quantified [26].

$\alpha$-Smooth Muscle Actin ( $\alpha$-SMA) and Collagen III

Co-Staining: Fibrosis

Dual staining was used to quantify the level of collagen type III in the adventitia and $\alpha$-SMA in the media of the arteries in the proximal tubules areas. Briefly, the sections were incubated first with 1:50 rabbit anti-collagen type III and then with 1:50 mouse anti- $\alpha$-SMA overnight, washed and stained with 1:300 mixed donkey and anti-rabbit (collagen type II) and donkey anti-mouse $(\alpha-$ SMA $)$ and signal intensities quantified.

VVG Staining for Tubulointerstitial Fibrosis

Sections were evaluated with VVG stain as previously described [28]. Slides were viewed with a Nikon 50i microscope and images captured.

\section{Statistical Analysis}

All values are expressed as mean \pm SE. Statistical analyses were performed in SPSS 13.0 using ANOVA with Fisher's LSD and Student's t test for paired analysis.

\section{Results}

\section{Nebivolol Reduced Systolic Blood Pressure, Urinary}

Protein and $\beta-N A G$

Administration of nebivolol resulted in a small systolic blood pressure reduction and urinary protein excretion in the Ren2 [34]. In the R2-N there was a trend in the $\mathrm{R} 2-\mathrm{C}$ for increased urinary $\beta-\mathrm{NAG}$ that was reduced in the R2-N (p<0.05) (fig. 1a).

\section{Nebivolol Attenuates Abnormal Ultrastructural}

Remodeling in the PTC

PTC of R2-C decreased the number and length of the electron-dense canaliculi, decreased dense apical tubules, and endosomes (fig. 1b). Nebivolol increased in both number and length of canaliculi so that they appeared similar to the SD-C.

\section{Nebivolol Treatment Restored Decreased Megalin in} the Ren2 Tubulointerstitium

Megalin immunostaining was substantially reduced in the tubulointerstitium of $\mathrm{R} 2-\mathrm{C}(\mathrm{p}<0.05)$ and normalized following nebivolol treatment for 21 days (fig. 2). In- creases in megalin paralleled reductions in both albumin and $\beta-N A G$ with nebivolol treatment. Since megalin has been implicated in lysosomal biogenesis [15], this could help explain the decreased number of lysosomes in R2 kidneys and their restoration with 3 weeks of nebivolol treatment (fig. 3).

\section{Nebivolol Increases the Number of Lysosomes and Transcytotic Vesicles-Vacuoles}

There were decreased numbers of electron-dense lysosomes and electron-lucent transcytotic vesicles-vacuoles in the R2-C (fig. 3a), and treatment increased the number of both lysosomes and transcytotic vesicles-vacuoles (R2$\mathrm{N})$. In concert with the decreased lysosome numbers, LAMP2 was reduced in the Ren-C and restored following nebivolol treatment (fig. 3b).

\section{Nebivolol Attenuates Tubulointerstitial Oxidative \\ Stress in Ren2}

NADPH oxidase activity was increased in the R2-C tubulointerstitium and restored to similar levels of the SD-C following nebivolol treatment $(\mathrm{p}<0.05)$ (fig. 4a). A similar pattern was observed with subunits Racl and p47 $7^{\text {phox }}$ (fig 4b). A marker for peroxynitrite formation, 3$\mathrm{NT}$, was increased in the R2-C and decreased following treatment with nebivolol ( $\mathrm{p}<0.05)$ (fig. $4 \mathrm{c}$ ).

\section{Nebivolol Attenuates Early Perivascular and \\ Tubulointerstitial Fibrosis}

R2-C displayed marked basement membrane thickening in PTCs (fig. 5) attenuated with nebivolol treatment. Remodeling of the tubulointerstitium consisted of both periarteriolar adventitial expansion of extracellular matrix and tubulointerstitial fibrosis (fig. 6) findings attenuated with nebivolol treatment ( $\mathrm{p}<0.05)$. The $\mathrm{R} 2-\mathrm{C}$ tubulointerstitial regions also demonstrated spherical enlargement, loss of elongation of mitochondria and the ultrastructural changes were improved with treatment (not shown).

\section{Discussion}

Our understanding of the pathophysiology of PTC injury in response to Ang II and/or other growth factors and metabolic insults is very limited. However, the tubulointerstitial structural and functional abnormalities in the Ren2 kidney in this study are consistent with previously observed Ang II and associated oxidative stressmediated injury $[9,26]$. Treatment with nebiviolol for 3 
Fig. 1. Nebivolol improves urinary $(\beta-N A G)$ and $P T C$ endosomal remodeling in the Ren2 (R2). a $\beta-N A G$ is reduced with nebivolol treatment in the $\mathrm{R} 2\left[{ }^{* *} \mathrm{p}<\right.$ 0.05 treatment (+) compared to control (-)]. b Representative TEM images for ultrastructural analysis of the PTC endosomal region. R2 had fewer clathrincoated pits (inset) at the base of the microvillar brush border and decreased number and length of the electron-dense, elongated canalicular structures (arrows) at the base of the microvilli (bottom left). Nebivolol treatment in the R2 (bottom right) restores both length and number of the electron-dense elongated canalicular structures in the endosomal region of the PTC. $\mathrm{Mv}=$ Microvilla.
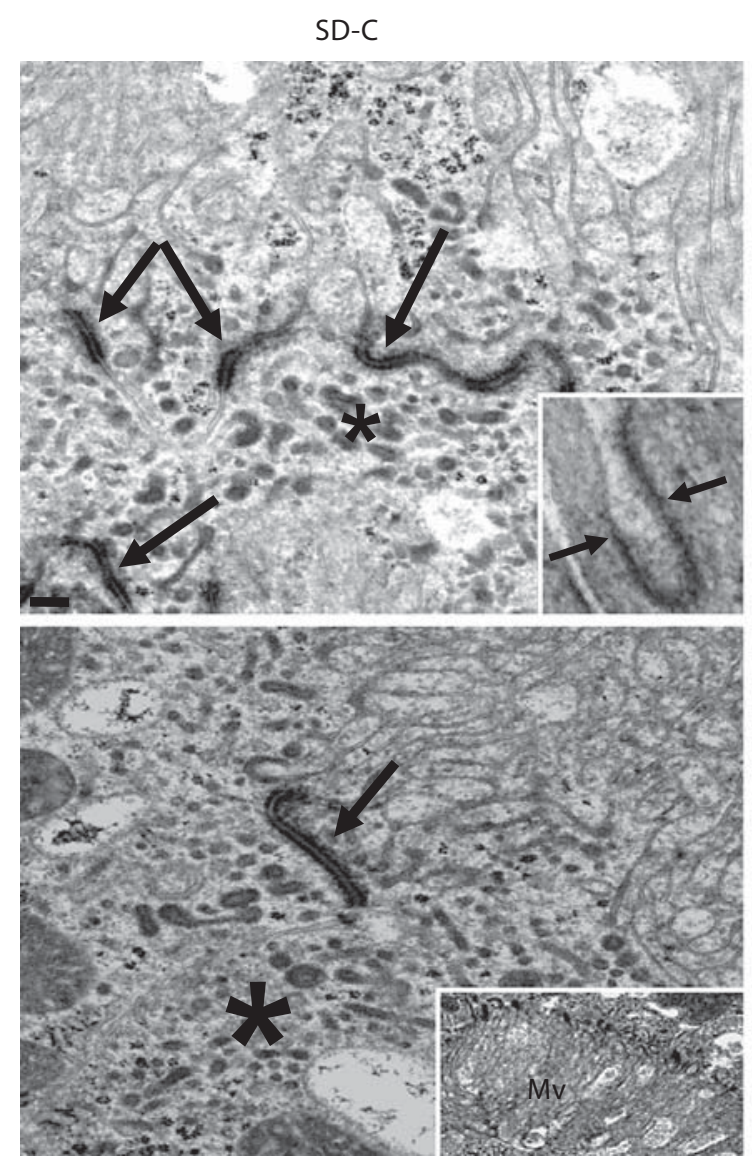

$\mathrm{R} 2-\mathrm{C}$
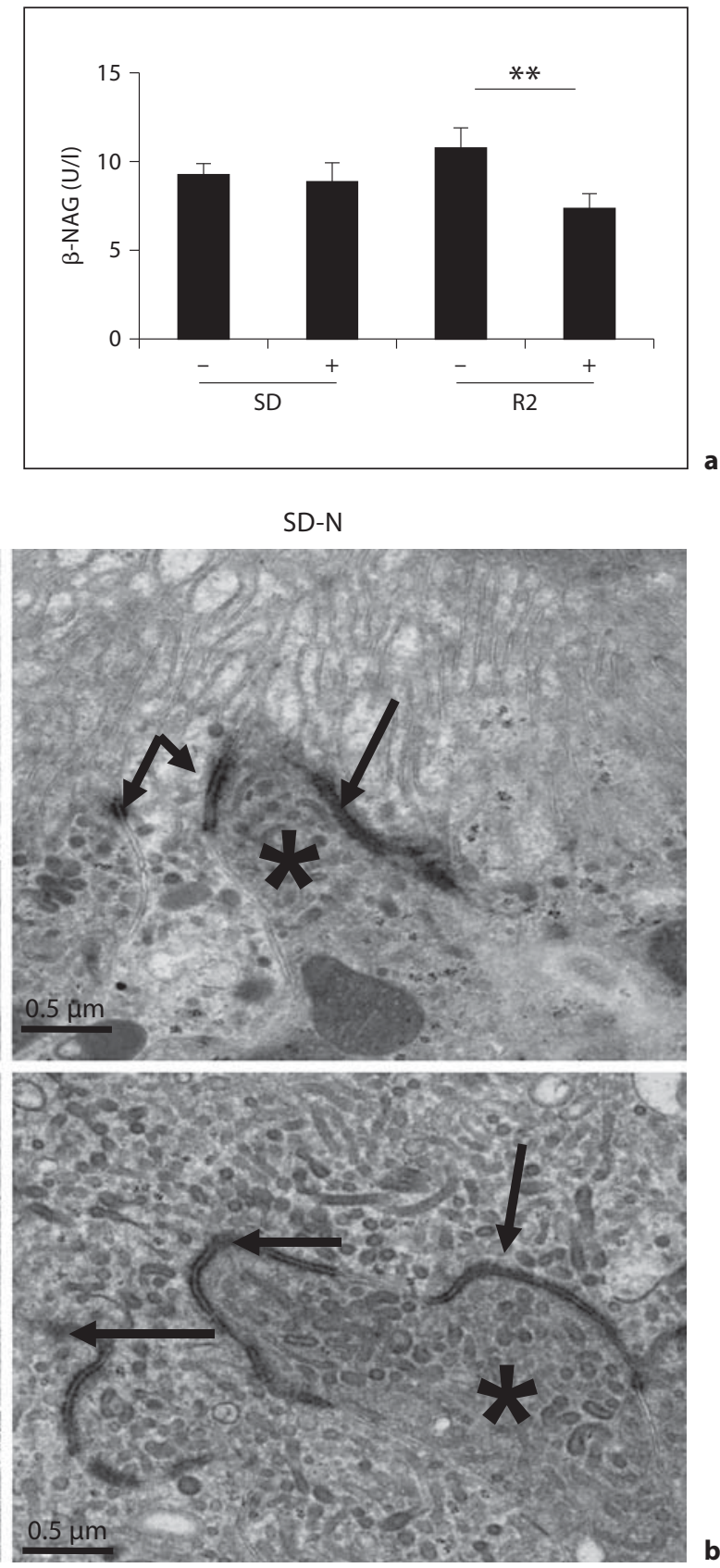

$\mathrm{R} 2-\mathrm{N}$ weeks substantially reduced tubulointerstitial oxidative stress and fibrosis as well as PTC structural abnormalities. In addition to reducing urinary albumin [34], nebivolol treatment substantially reduced urinary $\beta-N A G$. This small molecular weight protein is a $140-\mathrm{kDa}$ lysosomal enzyme that is present in high concentrations in PTC but is not typically excreted into the urine by normal PTCs. Increased $\beta-N A G$ is a marker for altered function and/or injury to the PTC $[9,43]$. Thus, in addition to reducing
NADPH oxidase activity, 3-NT levels, fibrosis and PTC ultrastructural structural abnormalities, this treatment also corrected the PTC functional abnormality as assessed by urine $\beta$-NAG levels $[9,43]$.

The decrease in urine $\beta$-NAG levels were paralleled by increased PTC megalin immunostaining in Ren2 following nebivolol treatment. Megalin is an endocytic receptor, belonging to the low-density lipoprotein family, which is well expressed in the PTC brush border, luminal 

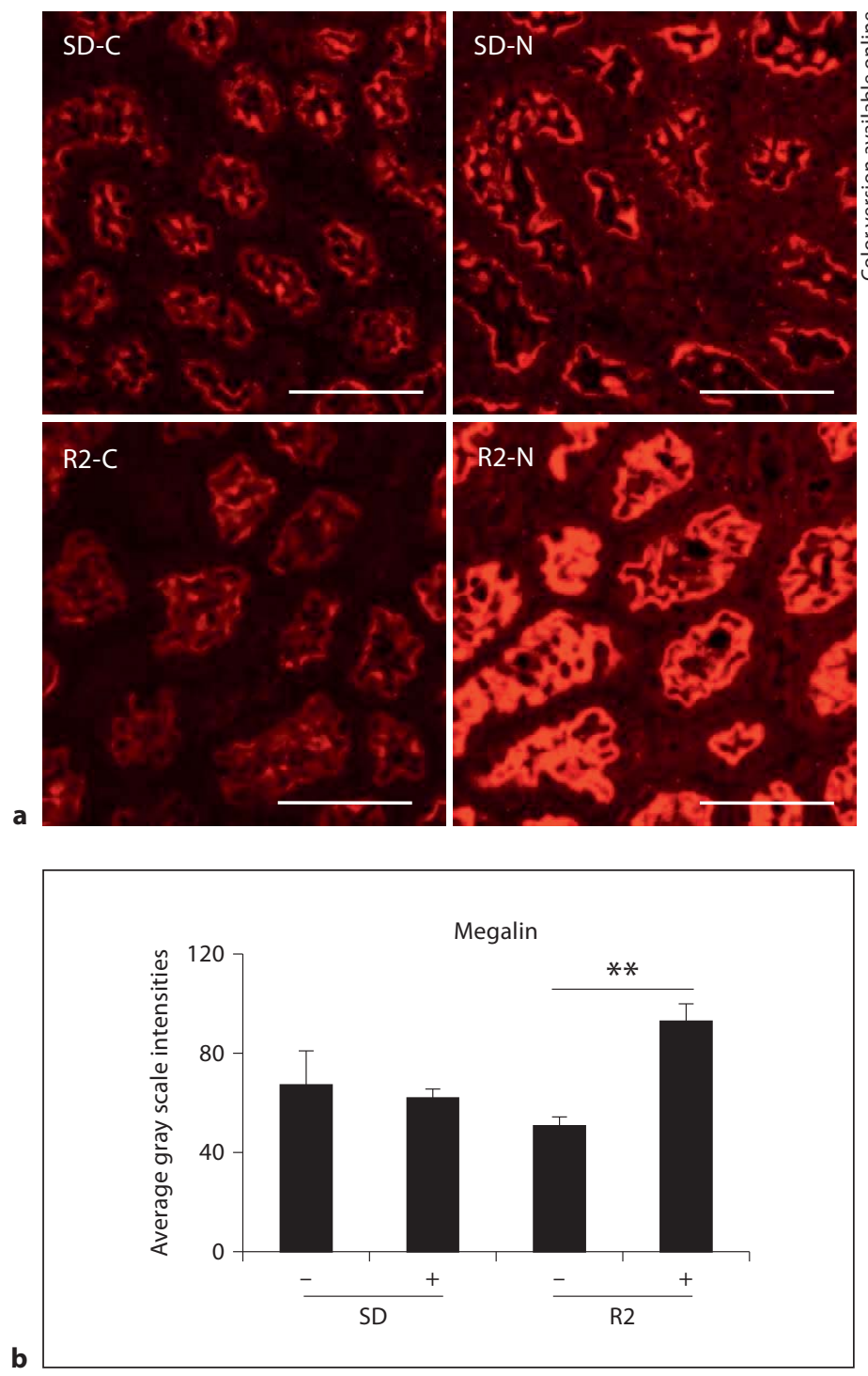

Fig. 2. Nebivolol restores megalin in the Ren2 (R2). Representative images from immunohistochemistry analysis of megalin (a) with corresponding average gray scale intensities (b). ** $\mathrm{p}<0.05$ treatment $(+)$ in R2 compared to control (-).

endosomes and lysosomes [8, 21, 22]. Its importance is evidenced by the fact that megalin-deficient mice have increased amounts of albumin and several other low molecular weight proteins in the urine [21, 22]. Consistent with our TEM observations in Ren 2 PTC, reduced megalin has been associated with loss of PTC endocytic invaginations/vesicles, reduced lysosomes and loss of canilicular integrity $[21,22]$. Extant data suggests that megalin may be involved in albumin reabsorption directly as a receptor albumin, and indirectly by affecting the ex- pression of cubilin which is coexpressed with megalin in the PTC brush border and the endocytic apparatus [21, 22]. Albumin is subsequently disassociated from these PTC receptors (megalin and cubilin) and transported via the endosomal/lysosomal degradation pathway, where it is degraded into its constituent polypeptides and amino acids. These degraded constituents are then transported across the basement membrane of the PTC and absorbed by adjacent interstitial capillaries and returned to the circulation $[22,23]$. This endocytic pathway is especially susceptible to metabolic and growth factors such as Ang II. In this regard, a recent study has demonstrated that increased Ang type 1A receptor-mediated growth pathway signaling reduces megalin expression in cultured PTCs [29]. Our data would suggest that this Ang II-mediated reduction in megalin expression can be corrected with an antihypertensive agent which reduces renal oxidant stress.

Data from this study suggests that nebivolol may correct the structural and functional PTC abnormalities seen in Ren 2 transgenic rats, in part by reducing NADPH oxidase and associated increases in tubulointerstitial oxidative stress. In this regard, treatment with nebivolol, like $\mathrm{AT}_{1} \mathrm{R}$ blockade [9], attenuates PTC injury in this model characterized by increased renal Ang II levels $[9,26]$. Ang II generates superoxide anions $\left(\mathrm{O}_{2}^{-}\right)$in cardiovascular tissue and the kidney largely by increasing NADPH oxidase activity that potentiates inflammation and fibrosis $[44,45]$. Despite our observation that nebivolol treatment improved mitochondrial structure, it is likely that the reduction in oxidative stress primarily reflected a reduction in NADPH oxidase activity rather than reductions in mitochondrial $\mathrm{O}_{2}^{-}$production [45-49]. These data collectively suggest that an increase in NADPH oxidase is a convergent pathway by which increased Ang II and/or albuminuria causes PTC injury, and that antihypertensive agents that reduce renal NADPH oxidase $[9,35-39]$ protect against tubulointerstitial fibrosis and preserve PTC ability to process albumin and other small molecular proteins that are filtered through the glomerulus.

The results of this investigation support the notion that a vasodilating $\beta$-blocker, unlike conventional $\beta$ blockers, provides renal-protective actions. A clinical study in hypertensive patients with type 2 diabetes showed that a vasodilating $\beta$-blocker, carvedilol, but not metoprolol, reduced albuminuria on top of RAS blockade [50]. The authors concluded that the beneficial effect of carvedilol may be related to an ability to reduce oxidative stress. It is suggested that nebivolol, like carvedilol, may 
SD-C
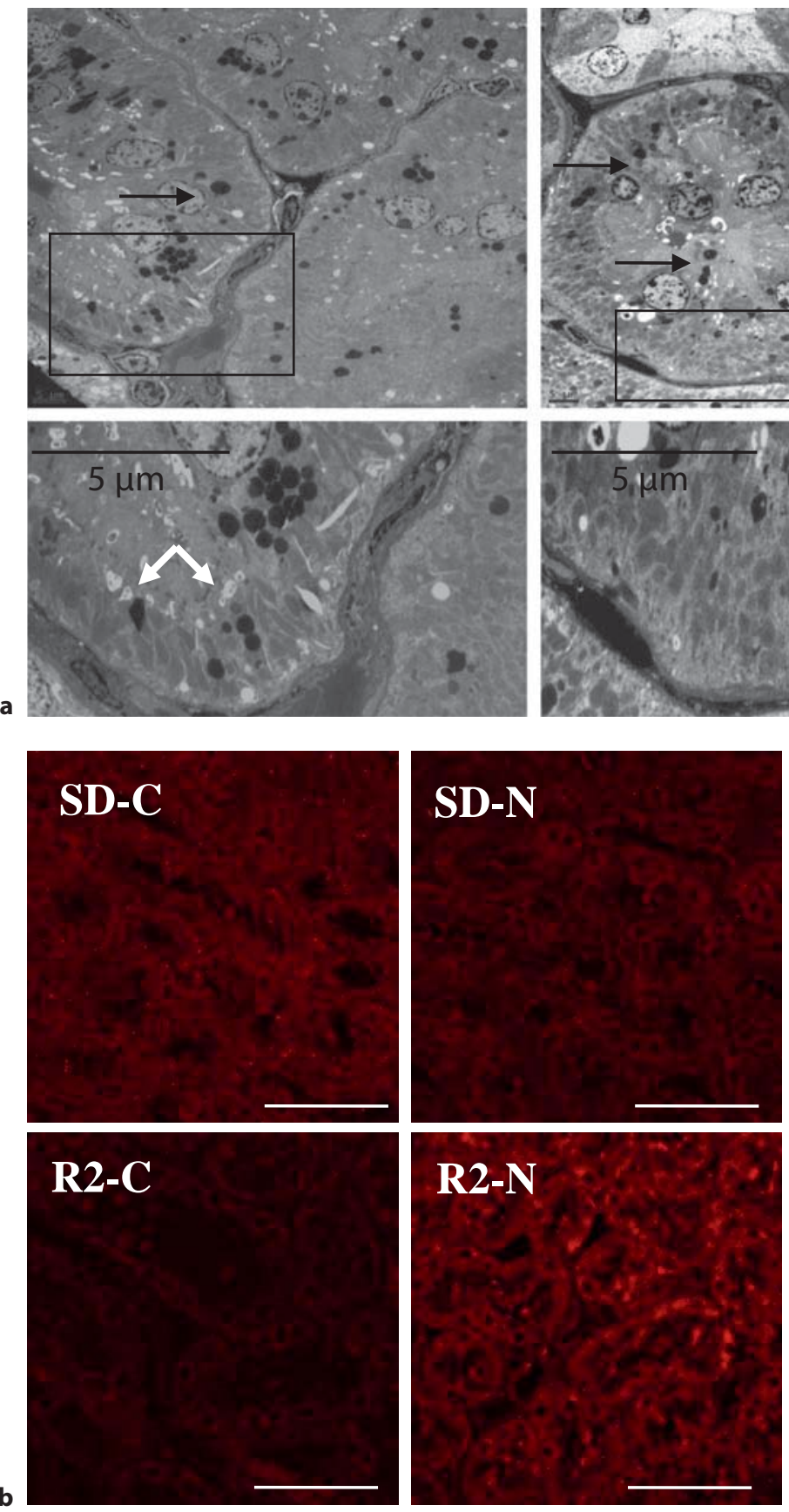

Fig. 3. Nebivolol restores decreased PTC lysosomes, apical and basilar vacuoles, and LAMP2 in the Ren2 (R2). a Representative TEM images of ultrastructural analysis of the R2 S-1 region of the PTC. R2-C (middle image) demonstrate decreased intense electron-dense (black) ovoid lysosomes (arrows) and electron-lucent (white) apical and basilar vacuoles (white arrows) compared to SD$\mathrm{C}$ (left image) restored with nebivolol treatment in the R2-N (right
R2-C
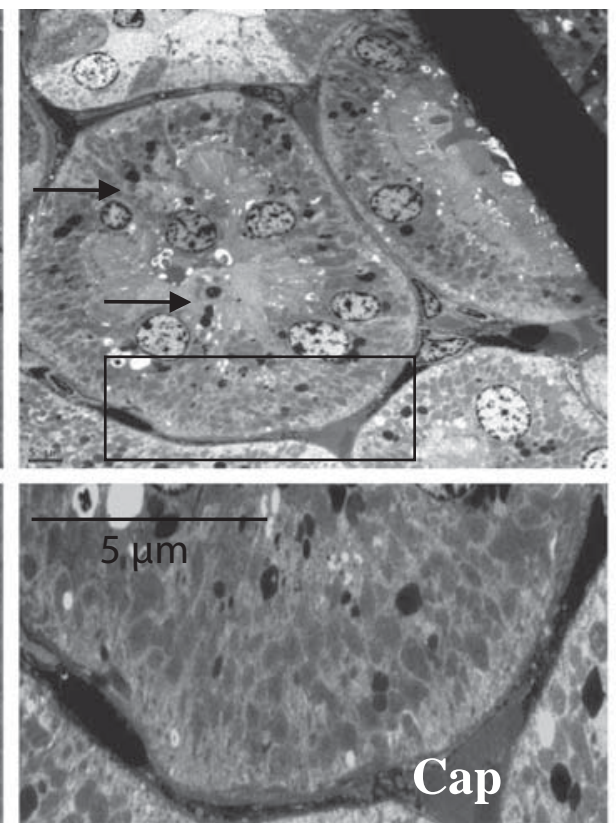

R2-N
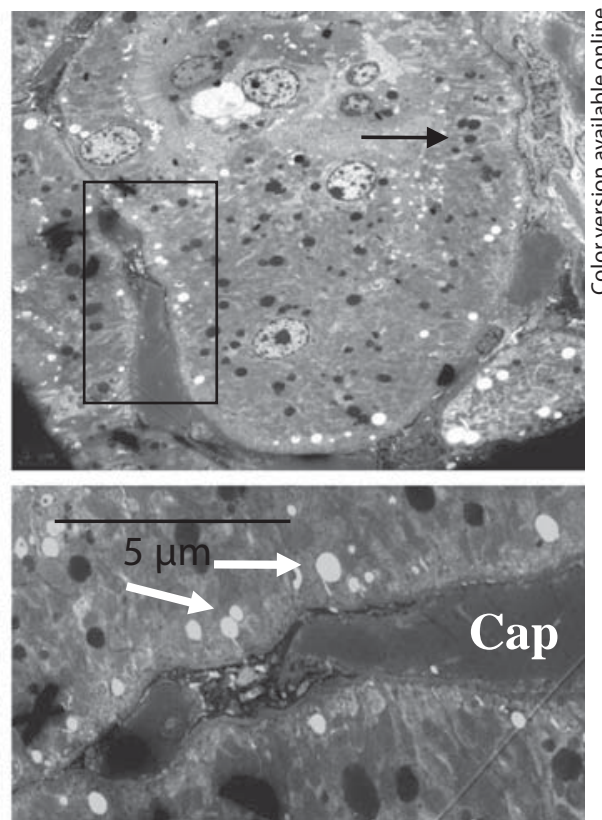

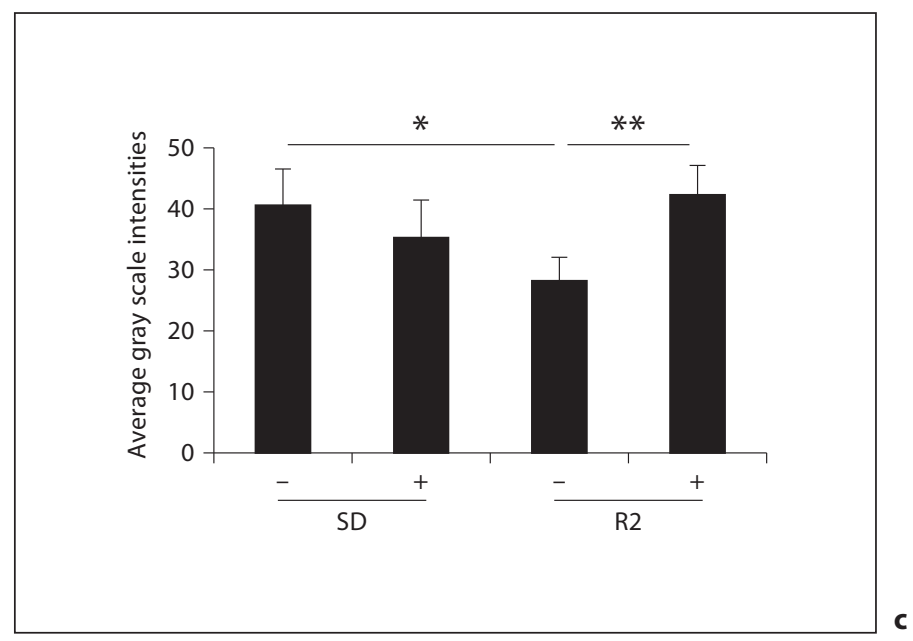

image). Below are higher magnification images to better demonstrate the electron-lucent basilar vacuoles. Cap = Capillary. $\mathbf{b}$ Representative images from immunohistochemistry analysis of LAMP2 with corresponding average gray scale intensities (c). ${ }^{*} \mathrm{p}<0.05$ untreated (-) R2 controls (-) compared to untreated (-) SD controls; ${ }^{* *} \mathrm{p}<0.05$ treatment $(+)$ compared to control (-). 
Fig. 4. Nebivolol attenuates kidney cortical tissue NADPH oxidase, subunits (Racl and $\mathrm{p} 47^{\mathrm{phox}}$ ), and 3-NT content in the transgenic Ren2 (R2) model. a Total NADPH oxidase enzyme activity. b Representative images of immunohistochemistry analysis of the NADPH oxidase subunits Racl and $\mathrm{p} 47^{\text {phox }}$ subunits with corresponding average gray scale intensities below. c 3 -NT staining as a marker of peroxynitrite $\left(\mathrm{ONOO}^{-}\right)$formation. ${ }^{*} \mathrm{p}<0.05$ untreated (-) R2 control (-) compared to untreated (-) SD control; ${ }^{* *} \mathrm{p}<0.05$ treatment $(+)$ compared to untreated control (-).

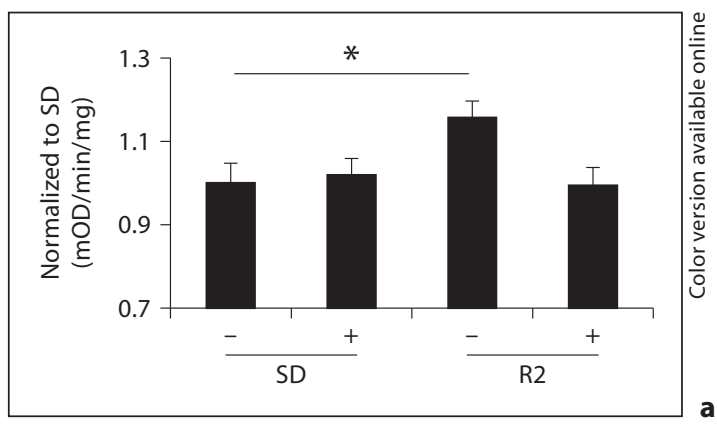

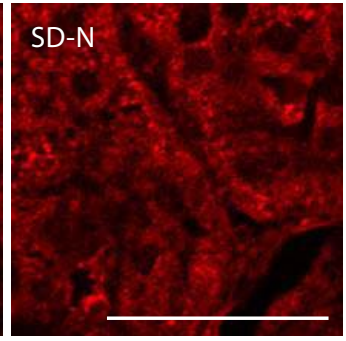
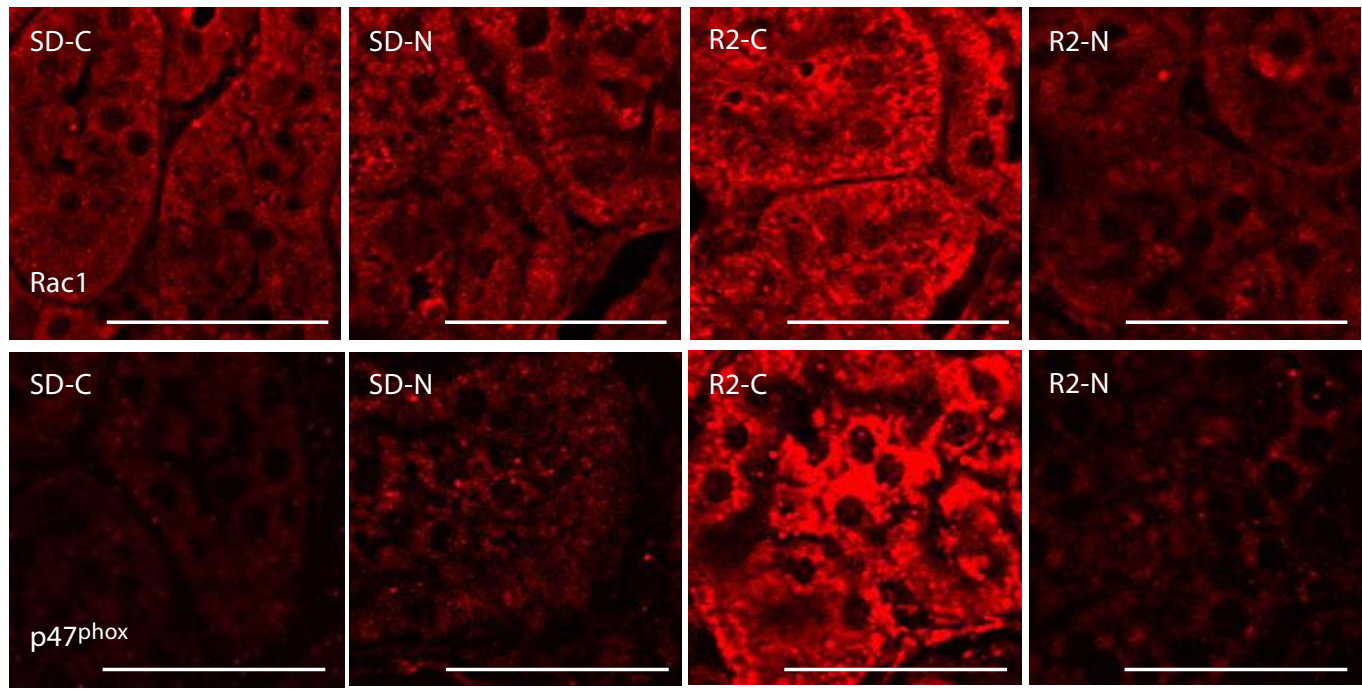

Rac1
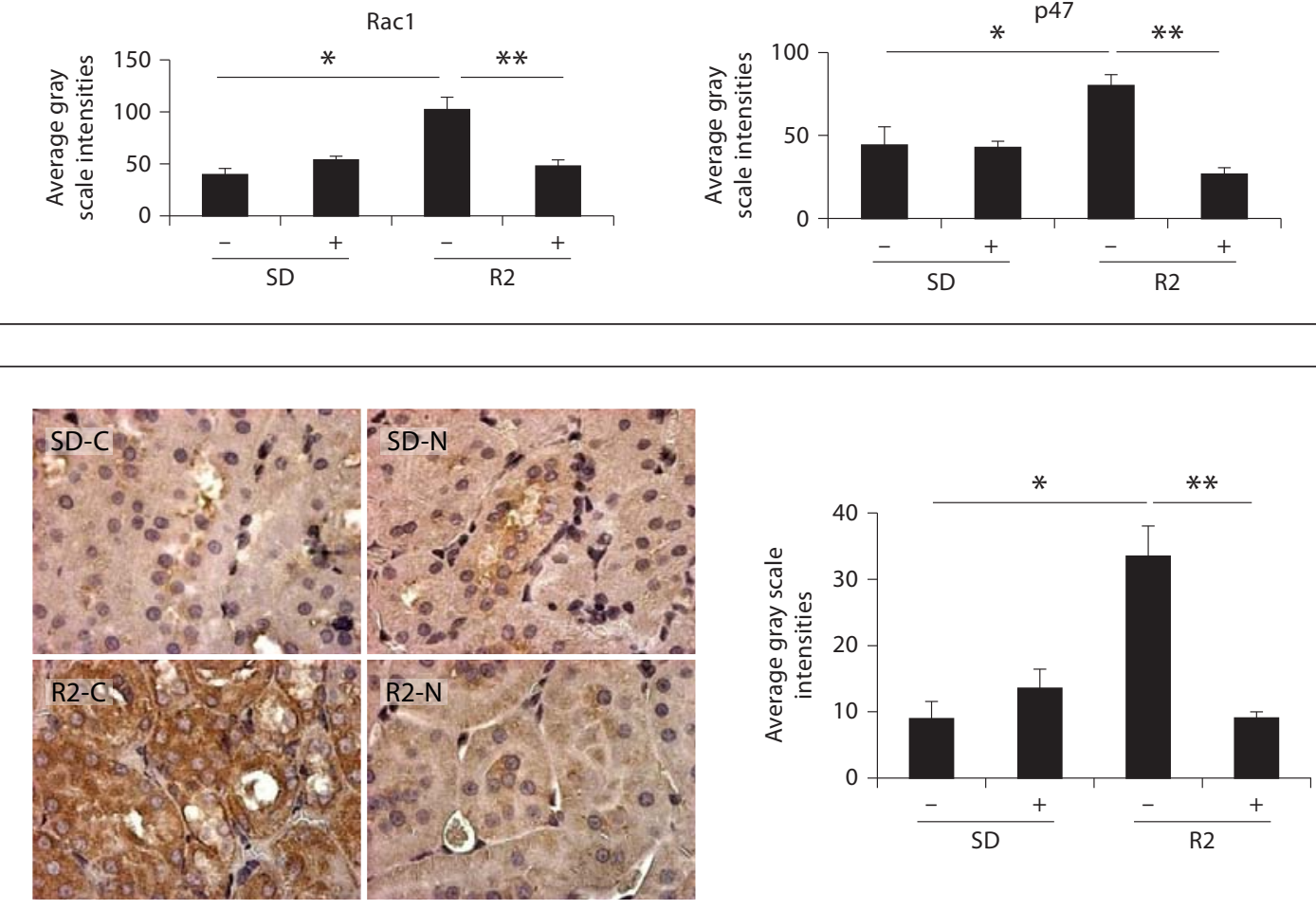
SD-C

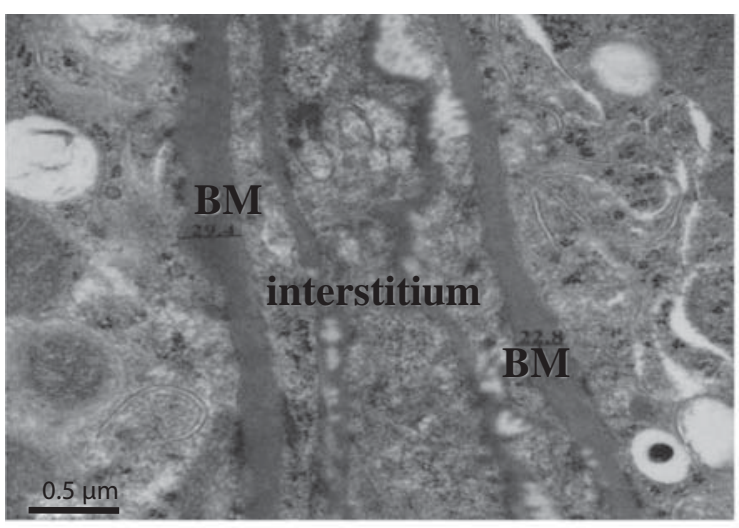

R2-C
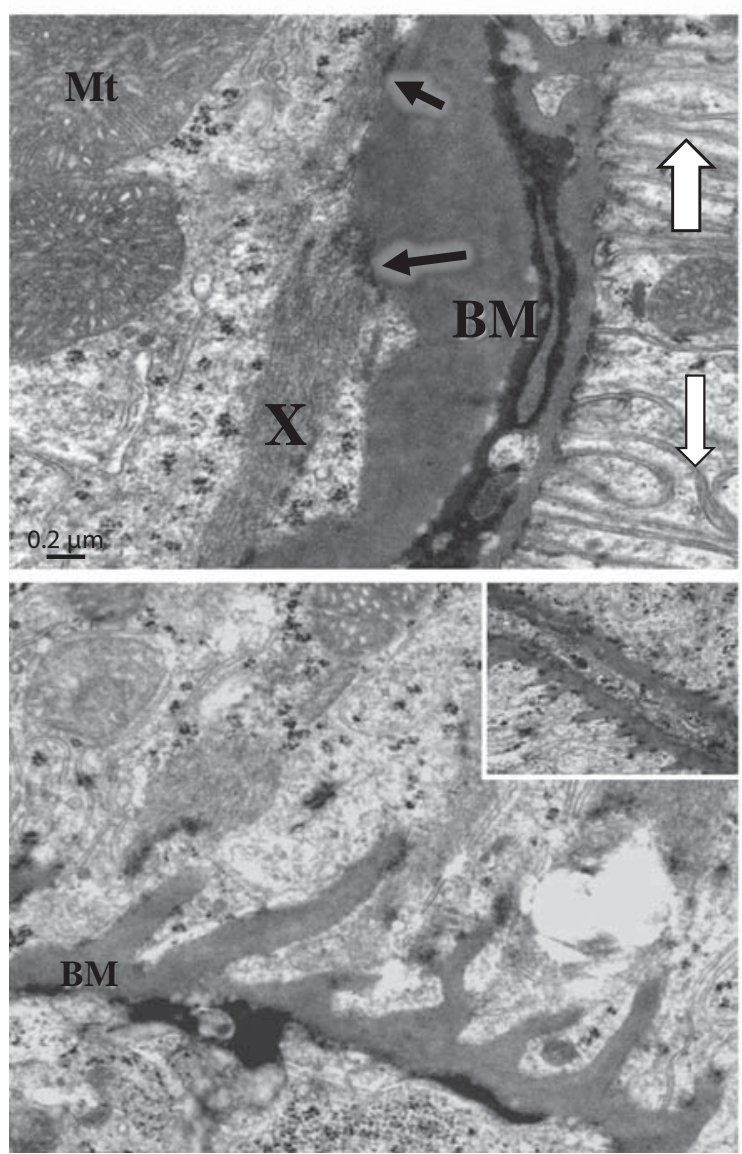

SD-N

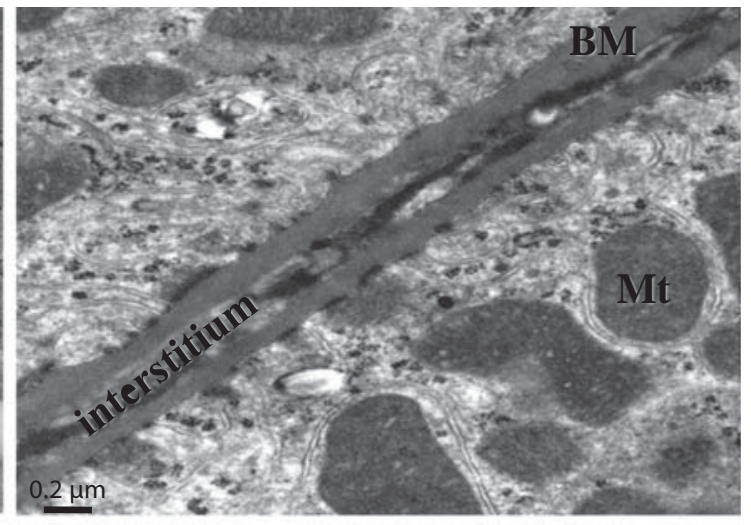

R2-N
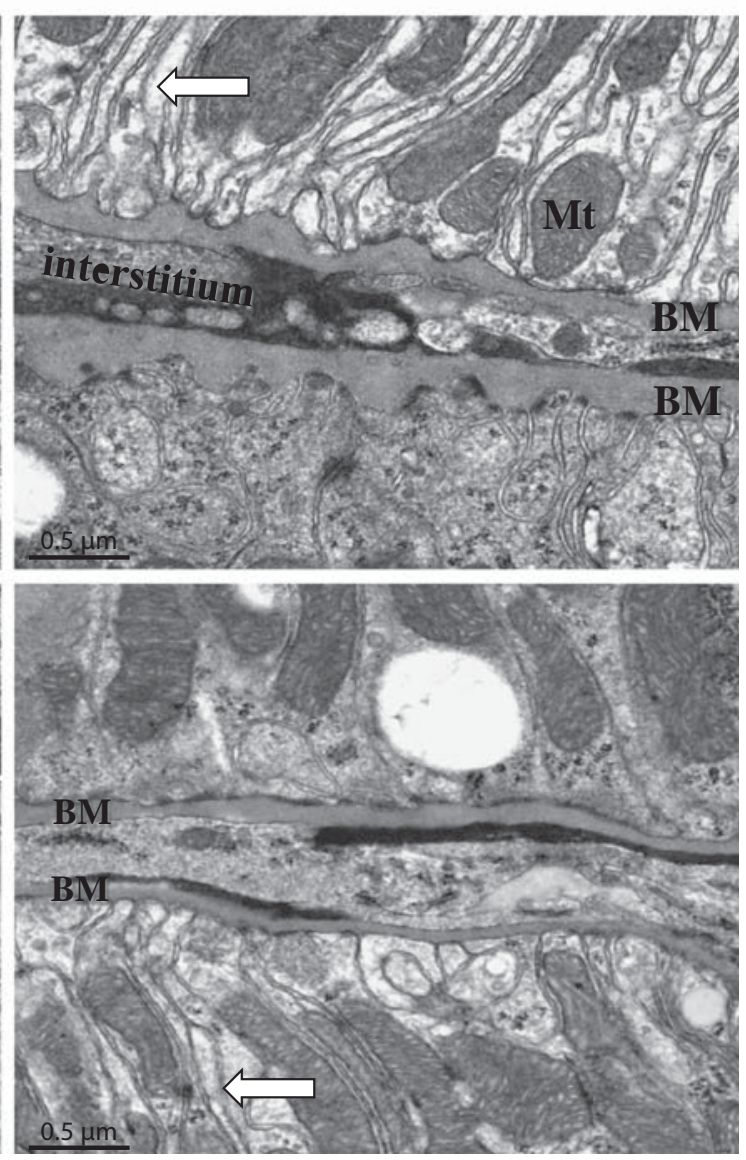

Fig. 5. Nebivolol attenuates PTC basement membrane (BM) thickening in the Ren2 (R2). Top panel represents images of the normal PTC BM in SD-C with no demonstrable remodeling changes following nebivolol treatment (SD-N). Bottom panel depicts the two types of BM thickening: the cytosolic layering-addition thickening (X) in the R2-C (top left). The more prevalent electron-dense finger-like protrusion BM thickening (bottom left) depicts the extracellular matrix thickening following the path of the invaginating basilar canaliculi. Note: nebivolol attenuates this BM thickening in the R2 (right images - R2-N). Mt = Mitochondria. 

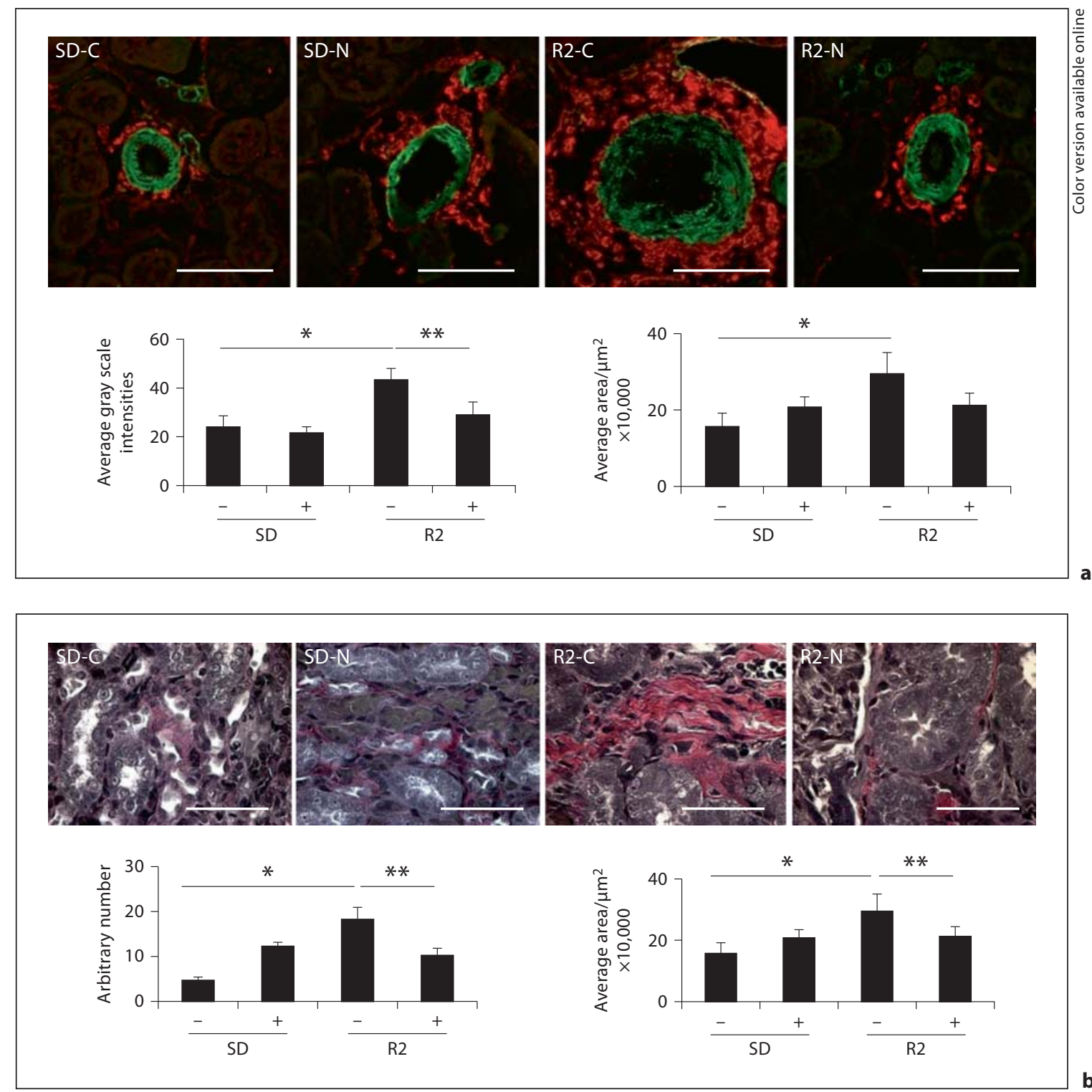

Fig. 6. Nebivolol attenuates perivascular arteriolar and tubulointerstitial fibrosis in the Ren2 (R2) model. a Representative images of immunohistochemistry analysis of $\alpha$-smooth muscle actin (green; colors in the online version only) and collagen type III (red) in interstitial arterioles with gray scale intensities below (left) and average area of periarteriolar fibrosis (right). b Repre- sentative VVG staining of tubulointerstital regions with corresponding measure of intensity (left) and average area (right). ${ }^{*} \mathrm{p}<0.05$ untreated $(-) \mathrm{R} 2$ control $(-)$ compared to untreated (-) SD-C; ${ }^{* *} \mathrm{p}<0.05$ treatment $(+)$ compared to untreated control $(-)$.

[36-39]. Similarly, our observation that nebivolol treatment reduced both peritubular and perivascular fibrosis is consistent with a previous experimental study comparing nebivolol and atenolol in a renal mass reduction [41] and those in a rat model of contrast-induced nephropathy [42] which demonstrated that nebivolol, but not atenolol, reduced renal fibrosis and improved NO-endothelial function. The authors concluded that reduced renal fi- 
brosis was attributable to decreased oxidative stress and/ or increased NO bioavailability in response to nebivolol but not atenolol treatment. Current data are consistent with the notion that nebivolol reduces tubulointerstitial oxidative stress along with fibrosis and other indicators of PTC functional and structural abnormalities.

\section{Acknowledgements}

This research was supported by NIH (R01 HL73101-01A1), Veterans Affairs Merit System 0018 (J.R.S.) and Career Development Award-2 and VISN15 (A.W.C.) as well as Forrest Research Institute. The authors wish to thank Becky Schneider, Nathan Rehmer and Brenda Hunter for their help in conducting the studies and preparing the manuscript.

\section{References}

1 Go AS, Chertow GM, Fan D, McCulloch DE, Hsu CY: Chronic kidney disease and the risks of death, cardiovascular events and hospitalization. N Engl J Med 2004;351: 1296-1305.

-2 Rahman M, Pressel S, Davis BR, Nwachuku C, Wright JT Jr, Whelton PK, Barzilay J, Batuman V, Eckfeldt JH, Farber MA, Franklin S, Henriquez M, Kopyt N, Louis GT, Saklayen M, Stanford C, Walworth C, Ward H, Wiegmann T, ALLHAT Collaborative Research Group: Cardiovascular outcomes in high-risk hypertensive patients stratified by baseline glomerular filtration rate. Ann Intern Med 2006;144:172-180.

$\checkmark 3$ Sarafidis PA, Whaley-Connell A, Sowers JR Bakris GL: Cardiometabolic syndrome and chronic kidney disease: what is the link? J Cardiometab Syndr 2006;1:58-65.

$\checkmark 4$ Sowers JR: Metabolic risk factors and renal disease. Kidney Int 2007;71:719-720.

$\checkmark 5$ Eddy AA: Molecular insights into renal interstitial fibrosis. J Am Soc Nephrol 1996;7: 2495-2508.

-6 Okada H, Kalluri R: Cellular and molecular pathways that lead to progression and regression of renal fibrogenesis. Curr Mol Med 2005;5:467-474.

$\checkmark 7$ Hayden MR, Chowdhury NA, Witte L, Sowers JR: Microalbuminuria and proximal tubule remodeling in the cardiometabolic syndrome. J Cardiometab Syndr 2006;1:107114.

8 Birn H, Christensen EI: Renal albumin absorption in physiology and pathology. Kidney Int 2006;69:440-449.

$\checkmark 9$ Hayden MR, Chowdhury NA, Cooper SA, Whaley-Connell A, Habibi J, Witte L, Wiedmeyer C, Manrique CM, Lastra G, Ferrario C, Stump C, Sowers JR: Proximal tubule microvilli remodeling and albuminuria in the Ren2 transgenic rat. Am J Physiol Renal Physiol 2007;292:F861-F867.

-10 Russo LM, Sandoval RM, McKee M, Osicka TM, Collins AB, Brown D, Molitoris BA, Comper WD: The normal kidney filters nephrotic levels of albumin retrieved by proximal tubule cells: retrieval is disrupted in nephrotic states. Kidney Int 2007;71:504-513.
11 Baines RJ, Brunskill NJ: The molecular interactions between filtered proteins and proximal tubular cells in proteinuria. Nephron Exp Nephrol 2008;110:e67-e71.

12 Comper WD, Hilliard LM, Nikolic-Paterson DJ, Russo LM: Disease-dependent mechanisms of albuminuria. Am J Physiol Renal Physiol 2008;295:F1589-F1600.

13 Russo LM, Sandoval RM, Campos SB, Molitoris BA, Comper WD, Brown D: Impaired tubular uptake explains albuminuria in early diabetic nephropathy. J Am Soc Nephrol 2009;20:489-494.

14 Jarad G, Miner JH: Albumin, where art thou? J Am Soc Nephrol 2009;20:455-457.

15 Christensen EI, Verroust PJ, Nielsen R: Receptor-mediated endocytosis in renal proximal tubule. Pflugers Arch 2009;458:10391048.

16 Russo LM, Sandoval RM, McKee M, Osicka TM, Collins AB, Brown D, Molitoris BA, Comper WD: The normal kidney filters nephrotic levels of albumin retrieved by proximal tubule cells: retrieval is disrupted in nephrotic states. Kidney Int 2007;71:504-513.

17 Guo DF, Tardif V, Ghelima K, Chan JS, Ingelfinger JR, Chen X, Chenier I: A novel angiotensin II type 1 receptor-associated protein induces cellular hypertrophy in rat vascular smooth muscle and renal proximal tubular cells. J Biol Chem 2004;279:21109_ 21120.

-18 Caruso-Neves C, Kwon SH, Guggino WB: Albumin endocytosis in proximal tubule cells is modulated by angiotensin II through an AT2 receptor-mediated protein kinase $B$ activation. Proc Natl Acad Sci USA 2005; 102 : 17513-17518.

19 Li XC, Carretero OA, Navar LG, Zhuo JL: AT1 receptor-mediated accumulation of extracellular angiotensin II in proximal tubule cells: role of cytoskeleton microtubules and tyrosine phosphatases. Am J Physiol Renal Physiol 2006;291:F375-F383.

20 Kobori H, Nangaku M, Navar LG, Nishiyama A: The intrarenal renin-angiotensin system: from physiology to the pathobiology of hypertension and kidney disease. Pharmacol Rev 2007;59:251-257.
-21 Verroust PJ, Birn H, Nielsen R, Kozyraki R Christensen EI: The tandem endocytic receptors megalin and cubilin are important proteins in renal pathology. Kidney Int 2002; 62:745-756.

22 Christensen EI, Nielsen R: Role of megalin and cubilin in renal physiology and pathology. Rev Physiol Biochem Pharmacol 2007; 158:1-22.

23 Mitchell KD, Jacinto SM, Mullins JJ: Proximal tubular fluid, kidney, and plasma levels of angiotensin II in hypertensive Ren-2 transgenic rats. Am J Physiol Renal Physiol 1997;273:F246-F253.

24 Zhuo J, Ohishi M, Mendelsohn FA: Roles of AT1 and AT2 receptors in the hypertensive Ren-2 gene transgenic rat kidney. Hypertension 1999;33:347-353.

25 Hartner A, Porst M, Klanke B, Cordasic N, Veelken R, Hilgers KF: Angiotensin II formation in the kidney and nephrosclerosis in the Ren-2 hypertensive rats. Nephrol Dial Transplant 2006;21:1778-1795.

26 Whaley-Connell AT, Chowdhury NA, Hayden MR, Stump CS, Habibi J, Wiedmeyer CE, Gallagher PE, Tallant EA, Cooper SA Link CD, Ferrario C, Sowers JR: Oxidative stress and glomerular filtration barrier injury: role of the renin-angiotensin system in the Ren2 transgenic rat. Am J Physiol Renal Physiol 2006;291:F1308-F1314.

-27 Patni H, Mathew JT, Luan L, Franki N, Chander PH, Singhal PC: Aldosterone promotes proximal tubular cell apoptosis: role of oxidative stress. Am J Physiol Renal Physiol 2007;293:F1065-F1071.

28 Whaley-Connell A, Habibi J, Wei Y, Gutweiler A, Jellison J, Wiedmeyer CE, Ferrario CM, Sowers JR: Mineralocorticoid receptor antagonism attenuates glomerular filtration barrier remodeling in the transgenic Ren 2 rat. Am J Physiol Renal Physiol 2009;296: F1013-F1022.

-29 Hosojima M, Sato H, Yamamoto K, Kaseda R, Soma T, Kobayashi A, Suzuki A, Kabasawa $\mathrm{H}$, Takeyama A, Ikuyama $\mathrm{K}$, Iino $\mathrm{N}$, Nishiyama A, Thekkumkara TJ, Takeda T, Suzuki Y, GejyoF, Saito A: Regulation of megalin expression in cultured proximal tubule cells by angiotensin II type 1 A receptorand insulin-mediated signaling cross talk. Endocrinology 2009;150:871-878. 
30 Wei Y, Whaley-Connell AT, Chen K, Habibi J, Uptergrove GME, Clark SE, Stump CS, Ferrario CM, Sowers JR: NADPH oxidase contributes to vascular inflammation, insulin resistance, and remodeling in the transgenic (mRen2) rat. Hypertension 2007;50: 384-391.

- 31 Nishioka T, Callahan MF, Li P, Ferrario CM, Ganten D, Morris M: Increased central angiotensin and osmotic responses I the Ren-2 transgenic rat. Hypertension 1999;33:385388.

-32 Augustyniak RA, Tuncel M, Zhang W, Toto RD, Victor RG: Sympathetic overactivity as a cause of hypertension in chronic renal failure. J Hypertens 2002;20:3-9.

-33 Neumann J, Ligtenberg G, Klein II, Koomans HA, Blankestijn PJ: Sympathetic hyperactivity in chronic kidney disease: pathogenesis, clinical relevance, and treatment. Kidney Int 2004;65:1568-1576.

- 34 Whaley-Connell A, Habibi J, Johnson M, Timon R, Rehmer N, Rehmer J, Wiedmeyer C, Ferrario CM, Sowers JR: Nebivolol reduces proteinuria and renal NADPH oxidasegenerated reactive oxygen species in the transgenic Ren2 rat. Am J Nephrol 2009;30: 354-360.

-35 Tzemos N, Lim PO, MacDonald TM: Nebivolol reverses endothelial dysfunction in essential hypertension: a randomized, doubleblind, crossover study. Circulation 2001;104: 511-514.

-36 Kalinowski L, Dobrucki LW, SzczepanskaKonkel M, Jankowski M, Martyniec L, Angielski S, Malinski T: Third-generation $\beta$ blockers stimulate nitric oxide release from endothelial cells through ATP efflux: a novel mechanism for antihypertensive action. Circulation 2003;107:2747-2752.
37 Fratta Pasini A, Garbin U, Nava MC, Stranieri C, Davoli A, Sawamura T, Lo Cascio V, Cominacini L: Nebivolol decreases oxidative stress in essential hypertensive patients and increases nitric oxide by reducing its oxidative inactivation. J Hypertens 2005;23:589596.

38 Gupta S, Wright HM: Nebivolol: a highly selective $\beta_{1}$-adrenergic receptor blocker that causes vasodilation by increasing nitric oxide. Cardiovasc Ther 2008;26:189-202.

39 Georgescu A, Pluteanu F, Flonta ML, Badila E, Dorobantu M, Popov D: The cellular mechanisms involved in the vasodilator effect of nebivolol on the renal artery. Eur J Pharmacol 2005;508:159-166.

40 Pires MJ, Rodriquez-Pena AB, Arevalo M, Cenador B, Evangelista S, Esteller A, Sanchez-Rodriguez A, Colaco A, Lopez-Novoa JM: Long-term nebivolol administration reduces renal fibrosis and prevents endothelial dysfunction in rats with hypertension induced by renal mass reduction. Hypertension 2007;25:2486-2496.

41 Toprak O, Cirit M, Tanrisev M, Yazici C, Canoz O, Sipahiogiu M, Uzum A Ersoy R, Sozmen EY: Preventive effect of nebivolol on contrast-induced nephropathy in rats. Nephrol Dial Transplant 2008;23:853-859.

42 Gschwend S, Haug MB, Nierhaus M, Schulz A, Vetter R, Kossmehl P, Orzechowski HD, Scholze J, Rothermund L, Kreutz R: Shortterm treatment with a $\beta$-blocker with vasodilative capacities improves intrarenal endothelial function in experimental renal failure. Life Sci 2009;85:431-437.

43 Bosomworth MP, Aparicio SR, Hay AW: Urine N-acetyl-D-glucosaminidase - a marker of tubular damage? Nephrol Dial Transplant 1999;14:620-626.

-44 Hayden MR, Whaley-Connell A, Sowers JR: Renal redox stress and remodeling in metabolic syndrome, type 2 diabetes mellitus, and diabetic nephropathy: paying homage to the podocyte. Am J Nephrol 2005;25:553569.
45 Whaley-Connell A, Habibi J, Nistala R, Cooper SA, Karuparthi PR, Hayden MR, Rehmer N, DeMarco VG, Andresen BT, Wei Y, Ferrario $\mathrm{C}$, Sowers JR: Attenuation of angiotensin II-mediated NADPH oxidase activation and glomerular filtration barrier remodeling with statin treatment. Hypertension 2008;51:474-480

46 Christensen EI, Willnow TE: Essential role of megalin in renal proximal tubule for vitamin homeostasis. J Am Soc Nephrol 1999;10: 2224-2236.

47 Nielsen R, Courtoy PJ, Jacobsen C, Dom G, Lima WR, Jadot M, Willnow TE, Devuyst O, Christensen EI: Endocytosis provides a major alternative pathway for lysosomal biogenesis in kidney proximal tubular cells. Proc Natl Acad Sci USA 2007;104:54075412.

48 Brooks C, Wei Q, Cho SG, Dong Z: Regulation of mitochondrial dynamics in acute kidney injury in cell culture and rodent models. J Clin Invest 2009;119:1275-1285.

49 Brooks C, Wei Q, Cho SG, Dong Z: Regulation of mitochondrial dynamics in acute kidney injury in cell culture and rodent models. J Clin Invest 2009;119:1275-1285.

50 Bakris GL, Fonseca V, Katholi RE, McGill JB, Messerli F, Phillips RA, Raskin P, Wright JT Jr, Waterhouse B, Lukas MA, Anderson KM, Bell DS, GEMINI Investigators: Differential effects of $\beta$-blockers on albuminuria in patients with type 2 diabetes. Hypertension 2005;46:1309-1315.

51 Hart PD, Bakris GL: Should $\beta$-blockers be used to control hypertension in people with chronic kidney disease? Semin Nephrol 2007;27:555-564 